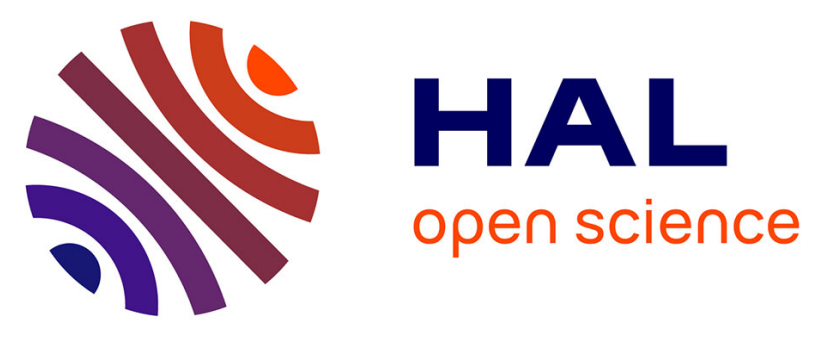

\title{
Efficient transfection of Xenobiotic Responsive Element-biosensor plasmid using diether lipid and phosphatidylcholine liposomes in differentiated HepaRG cells
}

Maxime Demazeau, Nicolas Quesnot, Nicolas Ripoche, Claudine Rauch, Jelena Jeftić, Fabrice Morel, Fabienne Gauffre, Thierry Benvegnu, Pascal Loyer

\section{- To cite this version:}

Maxime Demazeau, Nicolas Quesnot, Nicolas Ripoche, Claudine Rauch, Jelena Jeftić, et al.. Efficient transfection of Xenobiotic Responsive Element-biosensor plasmid using diether lipid and phosphatidylcholine liposomes in differentiated HepaRG cells. International Journal of Pharmaceutics, 2017, 524 (1-2), pp.268-278. 10.1016/j.ijpharm.2017.03.080 . hal-01518045

\section{HAL Id: hal-01518045}

\section{https://hal-univ-rennes1.archives-ouvertes.fr/hal-01518045}

Submitted on 5 Jul 2017

HAL is a multi-disciplinary open access archive for the deposit and dissemination of scientific research documents, whether they are published or not. The documents may come from teaching and research institutions in France or abroad, or from public or private research centers.
L'archive ouverte pluridisciplinaire $\mathbf{H A L}$, est destinée au dépôt et à la diffusion de documents scientifiques de niveau recherche, publiés ou non, émanant des établissements d'enseignement et de recherche français ou étrangers, des laboratoires publics ou privés.

\section{()(1)(2)}

Distributed under a Creative Commons Attribution - ShareAlikel 4.0 International 
Efficient Transfection of Xenobiotic Responsive Element-biosensor plasmid using diether lipid and phosphatidylcholine liposomes in differentiated HepaRG cells

Maxime Demazeau ${ }^{1 \dagger}$, Nicolas Quesnot ${ }^{2 \dagger}$, Nicolas Ripoche ${ }^{1}$, Claudine Rauch ${ }^{2}$, Jelena Jeftić ${ }^{1}$, ${\text { Fabrice } \text { Morel }^{2} \text {, Fabienne Gauffre }}^{3^{*}}$, Thierry Benvegnu ${ }^{1 *}$, Pascal Loyer ${ }^{2 *}$

${ }^{1}$ Ecole Nationale Supérieure de Chimie de Rennes, Institut des Sciences Chimiques de Rennes, UMR 6226 CNRS, Plateforme SynNanoVect, Biogenouest, 11 allée de Beaulieu, CS 50837, 35708 Rennes Cedex 7, France.

${ }^{2}$ INSERM, INRA, Univ Rennes 1, Univ Bretagne Loire, Nutrition Metabolisms and Cancer (NuMeCan), Plateforme SynNanoVect, Biogenouest, Rennes, France.

${ }^{3}$ Institut des Sciences Chimiques de Rennes, UMR 6226 CNRS, Université de Rennes 1, Campus de Beaulieu, 263 Avenue du Général Leclerc, F-35042 Rennes Cedex, France

*Corresponding Fabienne Gauffre (fabienne.gauffre@univ-rennes1.fr); Thierry Benvegnu (thierry.benvegnu@ensc-rennes.fr); Pascal Loyer (pascal.loyer@univ-rennes1.fr)

${ }^{\dagger}$ These authors contributed equally to the work

Graphical abstract 


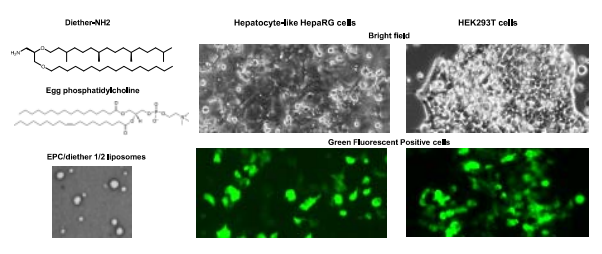

Keywords: archaeolipids; diether lipids; liposomes; transfection; HepaRG cells; biosensor plasmid

The authors declare no financial or commercial conflict of interest.

\section{Abstract}

In this study, we evaluated cationic liposomes prepared from diether- $\mathrm{NH}_{2}$ and egg phosphatidylcholine (EPC) for in vitro gene delivery. The impact of the lipid composition, i.e. the EPC and Diether- $\mathrm{NH}_{2}$ molar ratio, on in vitro transfection efficiency and cytotoxicity was investigated using the human HEK293T and hepatoma HepaRG cells known to be permissive and poorly permissive cells for liposome-mediated gene transfer, respectively. Here, we report that EPC/Diether- $\mathrm{NH}_{2}$-based liposomes enabled a very efficient transfection with low cytotoxicity compared to commercial transfection reagents in both HEK293T and proliferating progenitor HepaRG cells. Taking advantage of these non-toxic EPC/Diether- $\mathrm{NH}_{2}$-based liposomes, we developed a method to efficiently transfect differentiated hepatocyte-like HepaRG cells and a biosensor plasmid containing a Xenobiotic Responsive Element and a minimal promoter driving the transcription of the luciferase reporter gene. We demonstrated that the luciferase activity was induced by a canonical inducer of cytochrome P450 genes, the benzo[a]pyrene, and two environmental contaminants, the fluoranthene, a polycyclic aromatic 
hydrocarbon, and the endosulfan, an organochlorine insecticide, known to induce toxicity and genotoxicity in differentiated HepaRG cells. In conclusion, we established a new efficient lipofection-mediated gene transfer in hepatocyte-like HepaRG cells opening new perspectives in drug evaluation relying on xenobiotic inducible biosensor plasmids.

\section{Introduction}

In the liver, hepatocytes support the biotransformation of endogenous toxins and xenobiotics via the catalytic activities of phase I, II and III drug metabolism enzymes (DME). The liver being a major target of the toxicity of xenobiotics, the pharmaceutical industry faces a considerable challenge to evaluate the drug metabolism and toxicity in the hepatocytes. Toxicology studies rely on the use of both in vitro cell systems [Suter, 2006] and in vivo animal models prior to clinical trials in Humans.

The primary cultures of human hepatocytes are considered as the most pertinent in vitro cell system to predict xenobiotic metabolism and toxicity of synthetic compounds [Guillouzo and Guguen-Guillouzo, 2008]. However, the limited and unpredictable availability of human liver biopsies, the short lifespan of primary cultures and the functional variations in DME activities in hepatocytes isolated from different donors reduce the use of these models [Guillouzo and Guguen-Guillouzo, 2008]. Most of the hepatoma cell lines, which represent an unlimited source of hepatocytic cells, exhibit weak expressions of the major DME compared to primary cells limiting the assessment of hepatic toxicity [Wilkening et al., 2003]. In order to improve DME expressions, selected subclones of hepatoma cells such as the HepG2C3A expressing higher amounts of CYP have been established [Kelly, 1994] and recombinant derived hepatoma cell lines have been generated through stable transfection of DME's expression vectors [Hashizume et al., 2010] or liver specific transcription factors driving transcription of DME genes [Jover et al., 1998]. In contrast, the human progenitor HepaRG hepatoma cells [Gripon et al., 2002] show the remarkable ability to differentiate into cholangiocyte- or hepatocyte-like cells [Cerec et al., 2007 ; Dubois-Pot-Schneider et al., 2014] that spontaneously express the major phase I, II and III enzymes [Aninat et al., 2006 ; Dumont et al., 2010]. This cell line represents a valuable alternative in vitro model to primary hepatocytes for studying metabolism and toxicity of xenobiotics [Kanebratt and Andersson, 2008 ; Jossé et al., 2008 ; Legendre et al., 2009]. The metabolically competent HepaRG hepatocyte-like cells can be isolated from the cholangiocytes, plated at high density and maintained for to 2-3 weeks with a stable expression of DMEs [Corlu and Loyer, 2015], allowing chronic toxicity and genotoxicity studies [Quesnot et al., 2016]. 
The expression of DMEs in hepatocytes is strongly regulated at the transcriptional level by hormonal factors such as growth factors and cytokines [Fardel et al., 1992 ; Abdel Razzak et al., 1993 ; Langouet et al., 1995 ; Desmots et al., 2002], hypoxia [Legendre et al., 2009], endogenous noxious compounds and xenobiotics [Jetten et al., 2013]. An important aspect in the assessment of drug hepatotoxicity is the induction of DME's expression by xenobiotics to identify activation of metabolic pathways. The transcriptional regulation of DME gene may be achieved using different technical approaches of molecular biology such as the quantitative PCR of pre-selected genes or, on a larger scale, the gene profiling with DNA microarrays. These labour intensive experiments require relatively large amounts of cells and are not often compatible with the screening of a large collection of compounds. To overcome these problems rapid high-throughput cell-based assays that measure cell responses and gene induction are being developed to provide early warning on metabolic pathway activations and toxicity. Among these assays, whole cell biosensors in HepaRG [Pernelle et al. 2011 ; Tsuji et al., 2014] and HepG2 [Fery et al., 2010 ; Casabar et al., 2010 ; Blagus et al., 2014 ; Tsuji et al., 2014] hepatoma cell lines have been developed in order to analyze drug metabolism and cytotoxicity, to detect mitochondrial dysfunction and genotoxicity but also to evidence DME transcriptional gene modulations in hepatoma cells upon drug treatments [Fery et al., 2010 ; Casabar et al., 2010 ; Blagus et al., 2014 ; Tsuji et al., 2014]. In these studies, reporter genes such as luciferase and green fluorescent protein (GFP) are cloned downstream of partial DME gene promoters to design inducible reporter gene constructs transiently or stably transfected in hepatoma cells allowing an easy reading out to evidence modulations of DME gene transcription upon treatments by synthetic compounds.

The establishment of recombinant cell lines provides an unlimited source of cells but requires a time-consuming cell selection to isolate the cell populations or clones with genome integration(s) of the transgene. Alternatively, transient transfection is a much easier set-up but the gene transfer must be renewed for each experiment. In both strategies, the non-viral transfer of plasmids into primary hepatocytes and differentiated hepatoma cells is a difficult task because of the limited transfection efficiencies and the toxicity of chemical transfection reagents and electroporation procedures. Our laboratories have previously synthesized and characterized novel cationic lipids and electroporation procedures to improve the transfection of primary hepatocytes [Gilot et al., 2002] and hepatocyte-like HepaRG cells [Laurent et al., 2010]. Despite significant improvements in the efficiencies of gene delivery in these in vitro cells models, in most cases, the cytotoxicity remains a challenging issue and there is still an 
obvious need for the development of new liposomes allowing efficient transfection of plasmids while preserving the cell survival.

Since the first report on the use of diether-linked cationic lipid DOTMA as a synthetic nanocarrier for cationic liposome-mediated gene delivery by [Felgner et al., 1987] several cationic lipids possessing diether linkages between the hydrophobic domain and the positively charged head-groups have been described. These synthetic lipids include either a permanent cationic charge through the presence of a quaternary ammonium-type moiety (e.g. DOTMA) or a conditionally ionized head-group such as a tertiary amine group (e.g. DODMA). [Heyes et al., 2005]. Structural variations of the lipophilic domain were also investigated by varying the length of carbon chains and its saturation or insaturation levels [Liu et al., 2006]. It is noteworthy that the degree of saturation of diether-type cationic lipids was found to affect fusogenicity and cellular uptake when used to encapsulate nucleic acids. Furthermore, these synthetic lipids gave better in vivo transfection activities over their diester cationic counterparts [Ren et al., 1999]. Even if the cellular uptake by permanently ionized cationic lipid (DOTMA) based nanocarriers is generally higher than that of the lipoplexes made from ionizable cationic lipids, the endosomal escape step could be facilitated by the presence of ionizable amine moieties. These findings may be explained by the ability of some amine-type lipids to destabilize the endosomal membrane through the promotion of a bilayer transition to an inverted micelle or hexagonal $\left(\mathrm{H}_{\mathrm{II}}\right)$ phase. We have described the synthesis of a diether lipid characterized by the presence of a branched phytanyl chain and a saturated hexadecyl chain and incorporating a primary amine moiety (Diether- $\mathrm{NH}_{2}$ ) as an intermediate for the preparation of folate-equipped PEGylated archaeal lipid derivatives [Lainé et al., 2008]. Since this dietherlinked lipid was also found to exhibit a $\mathrm{H}_{\text {II }}$ phase (unpublished data), we hypothesized that it could be a suitable helper lipid for gene delivery application over the commonly used dioleoylphosphatidylethanolamine (DOPE) or cholesterol.

The main goal of this study was to characterize the gene delivery mediated by novel cationic liposomes prepared from Diether- $\mathrm{NH}_{2}$ combined with egg phosphatidylcholine (EPC). In particular, our attention was focused on the impact of the lipid composition (EPC/Diether$\mathrm{NH}_{2}$ molar ratio) on both in vitro transfection efficiency and cytotoxicity induced by the lipoplexes. Here, we demonstrated that EPC/Diether- $\mathrm{NH}_{2}$-based liposomes yielded a very efficient transfection with low toxicity compared to commercially available transfection reagents in both the permissive HEK293T and poorly permissive human hepatoma HepaRG cells. Taking advantage of these non-toxic EPC/Diether- $\mathrm{NH}_{2}$ liposomes, we describe the development and validation of a new biosensor system using differentiated hepatocyte-like 
HepaRG cells transiently transfected with a Xenobiotic Responsive Element (XRE) minimal promoter driving the transcription of the luciferase reporter gene. This biosensor plasmid was challenged with a prototypical inducer of cytochrome P450 genes, the benzo[a]pyrene [B(a)P] and two widespread environmental contaminants, the fluoranthene and endosulfan, known to induce toxicity and genotoxicity in metabolically competent HepaRG cells [Quesnot et al., 2016].

\section{Materials and methods}

\subsection{Liposome preparation and characterization}

The egg phosphatidylcholine EPC was purchased from Sigma (Saint Quentin Fallavier, France). The diether- $\mathrm{NH}_{2}$ was synthesized as previously described [Lainé et al., 2008]. The lipids were dissolved separately in chloroform and different amounts were mixed in glass tubes in order to obtain the various EPC and diether- $\mathrm{NH}_{2}$ ratios $(1 / 2,3 / 2$ and 5/2) prior to the liposome preparations. The chloroform was evaporated in a rotatory evaporator to form a homogenous dry film. The film was kept at $4^{\circ} \mathrm{C}$ for at least 1 hour (h) prior to the addition of $1 \mathrm{~mL}$ of distilled water. The tubes were incubated for $1 \mathrm{~h}$ in a water bath at $60^{\circ} \mathrm{C}$, briefly vortexed and sonicated for 4 cycles of $10 \mathrm{~min}$ at $40^{\circ} \mathrm{C}$. For size measurement (hydrodynamic diameter), the liposome suspensions were diluted in distilled water at the final concentration in lipids of $0.1 \mathrm{mg} / \mathrm{mL}$. The size measurements were performed using $400 \mu \mathrm{L}$ of these diluted liposome suspensions and a Nano ZS Zetasizer instrument (Malvern Instruments Ltd) according to the manufacturer's procedure. For the transmission electron microscopy (TEM), the diluted liposome samples $(0.1$ $\mathrm{mg} / \mathrm{mL}$ ) and the lipoplexes (see preparation in section 3.4) were absorbed on TEM grids prior to a contrast staining using uranyl acetate at $2 \%$ in water for 30 seconds. The imaging of the liposome and lipoplexes was made with a JEM-1400Plus (JEOL) microscope.

\subsection{Luciferase reporter gene construct}

DNA primers (Eurogentec) corresponding to the XRE (XRE consensus sequence of $46 \mathrm{bp}$ : 5'TTCTCACGCAACGCCGCGGCGCAGGCAAGCTCTTCTCACGCGAGCT3') derived from the alignment of previously identified XRE sequences [Fujisawa-Sehara et al., 1988] were annealed and cloned into the pGL3-basic vector digested using the KpnI (GGTACC, 5' end) and SacI (GAGCTC, 3' end) restriction sites (Supporting Figure 4). The XRE-pGL3 plasmid construct was sequenced to ensure the proper insertion of the annealed primers in the multiple cloning sites region of the pGL3-basic plasmid.

\subsection{HEK293T and HepaRG cell culture}

DMEM and William's E media were purchased from Eurobio (Les Ulis, France). Fetal calf serum (FCS) was obtained from Lonza (Levallois-Perret, France). Penicillin, streptomycin and 
L-glutamine were purchased from Life Technologies (Saint Aubin, France) while insulin was from Sigma (Saint Quentin Fallavier, France).

HEK293T cells were cultured in DMEM supplemented with $10 \%$ fetal calf serum (FCS) and 2\% L-glutamine. The HepaRG progenitor cells (Patent: PCT/FR02/02391, 2002) were seeded at a density of $3 \times 10^{4}$ cells $/ \mathrm{cm}^{2}$ and cultured in William's E medium supplemented with $10 \%$ FCS, 100 units $/ \mathrm{mL}$ penicillin and $100 \mu \mathrm{g} / \mathrm{mL}$ streptomycin, $5 \mu \mathrm{g} / \mathrm{mL}$ insulin, $2 \mathrm{mM}$ L-glutamine and $50 \mu \mathrm{M}$ hydrocortisone hemisuccinate. After two weeks, confluent quiescent cells commit to the hepatocytic lineage and express liver specific functions but the DME expression remains weak [Laurent et al., 2013]. To further enhance the hepatocyte differentiation, cells were cultured in the same medium supplemented with $2 \%$ dimethylsulfoxide (DMSO) for two more weeks [Laurent et al., 2013] prior to selective detachment using $0.05 \%$ trypsin solution (Gibco) and seeding of hepatocytes-like cells at a high density $\left(1.6 \times 10^{5}\right.$ cells $\left./ \mathrm{cm}^{2}\right)$, as previously described [Cerec et al., 2007 ; Laurent et al., 2013].

\subsection{Lipofection and electroporation}

The PGL3-basic and pmax-GFP plasmids were obtained from Promega and Lonza, respectively. These plasmids were bacterially amplified and purified using Nucleobond ${ }^{\circledR}$ Xtra Midi kit (Macherey-Nagel) and quantified by measuring the optical density at $260 \mathrm{~nm}$. Transfections of HEK293T and HepaRG cells with the pmax-GFP expression vector were performed using three commercially available transfection reagents the Lipofectamine $2000 \AA$, Lipofectamine FreeStyle ${ }^{\circledR}$ (ThermoFisher Scientic) and MACSfectin ${ }^{\circledR}$ (Miltenyi Biotec) and the Egg-PC/diether liposomes.

For transfection experiments, HEK293T $\left(10^{5}\right.$ cells $)$ or HepaRG cells $\left(10^{5}\right.$ progenitor cells and $2.5 \times 10^{5}$ hepatocyte-like cells) were seeded the day before the transfection in 24 well plates. For EPC/diether liposomes, 4 amounts of transfection reagents with a constant amount of DNA were used in order to test 4 charge ratios. The charge ratio is given by $R=$ (mass of reagent $/$ molecular weight of reagent $) /($ mass of DNA $/$ molecular weight of DNA). We used $R=$ $1(2 \mu \mathrm{L} / 2 \mu \mathrm{g}$ DNA), $R=2(4 \mu \mathrm{L} / 2 \mu \mathrm{g}$ DNA $), R=3(8 \mu \mathrm{L} / 2 \mu \mathrm{g}$ DNA $)$ and $R=4(16 \mu \mathrm{L} / 2 \mu \mathrm{g}$ DNA).

For Lipofectamine $2000 \AA$, Lipofectamine FreeStyle ${ }^{\circledR}$ and MACSfectin ${ }^{\circledR}$, the molecular mass of the compounds and/or concentration of reagents are not provided by suppliers. However, four volumes of transfection reagents $(\mu \mathrm{L})$ were used, as recommended by the manufacturers, with a constant amount of plasmid $(2 \mu \mathrm{g})$, giving 4 charge ratios: $R=1(0.75 \mu \mathrm{L} / 2 \mu \mathrm{g}$ DNA), $R=2(1.5 \mu \mathrm{L} / 2 \mu \mathrm{g}$ DNA $), R=3(3 \mu \mathrm{L} / 2 \mu \mathrm{g}$ DNA $)$ and $R=4(6 \mu \mathrm{L} / 2 \mu \mathrm{g}$ DNA $)$. 
The preparation of lipoplexes was similar for all reagents. For 1 well of $24-w e l l$ plates: the different volumes of transfection reagents and $2 \mu \mathrm{g}$ of plasmid DNA were separately diluted in $100 \mu \mathrm{L}$ of Opti-MEM medium (Gibco). The diluted transfection reagent and plasmid solutions were mixed, vortexed for $20 \mathrm{~s}$ and incubated at room temperature for $30 \mathrm{~min}$ allowing the formation of the lipolexes. The culture medium from the 24 well plates was discarded and renewed with $300 \mu \mathrm{L}$ of fresh culture medium without antibiotics. The $200 \mu \mathrm{L}$ of liposomeplasmid mixed solutions were added dropwise into the 24 well plates, which were incubated overnight with cells. The next day, the transfection medium was discarded and fresh medium containing antibiotics was added. The expression of the GFP or luciferase activity was analyzed at $48 \mathrm{~h}$ post-transfection.

Electroporation of hepatocyte-like HepaRG cells was performed using the Neon ${ }^{\mathrm{TM}}$ device (Life Technologies) as previously described [Laurent et al 2010] with the following parameters: one pulse of $1500 \mathrm{~V}$, during 20 milliseconds. Following electroporation, the cells were seeded at $2.5 \times 10^{5}$ cells $/ \mathrm{cm}^{2}$ in 48 well plates prior to the luciferase assay.

For the luciferase assays, hepatocyte-like HepaRG cells were co-transfected with control vector (pRL SV40, $50 \mathrm{ng}$ ) and the vectors containing firefly luciferase under the control of XRE promoter (pGL3-XREprom, $2 \mu \mathrm{g}$ ) using the EPC/diether liposomes 3/2 $(R=3)$ or by electroporation. The promoterless pGL3-luciferase construct $(2 \mu \mathrm{g})$ was also transfected in control cells providing the negative firefly luciferase activity controls.

\subsection{The thiazolyl blue tetrazolium bromide (MTT) assay}

The cytotoxicity was assessed using the MTT assay. Briefly, cells plated in 96 well plates were treated and incubated with MTT $(0.25 \mathrm{mg} / \mathrm{mL})$ in William's medium without FCS for $2 \mathrm{~h}$ at $37^{\circ} \mathrm{C}$. The crystals thus formed were dissolved in DMSO at room temperature for $5 \mathrm{~min}$, and the absorbance was measured at $490 \mathrm{~nm}$ with a microplate reader (Polarstar Omega, BMG Labtech). The MTT values reflecting mitochondrial enzymatic activities, which are directly correlated to the number of viable cells, were expressed in percentage relatively to the absorbance determined in control cultures that were not transfected.

\subsection{Fluorescence microscopy and flow cytometry}

The cell monolayers were washed with PBS before the observation by fluorescence microscopy using a Zeiss inverted microscope and the AxioVision software. Then, the cells were detached with trypsin and analyzed by flow cytometry (FACSCalibur Becton Dikinson) to quantify the fluorescence (Channel FL1H) emitted by the GFP positive cells. Cytometry data were analyzed 
using CellQuest software (Becton Dikinson) in order to obtain the percentage of GFP positive cells and the mean of fluorescence of the all cell population.

\subsection{Western blotting}

After discarding the culture medium, cell monolayers were washed once with cold PBS and lysed in $50 \mathrm{mM}$ HEPES pH 7.9, $150 \mathrm{mM}, \mathrm{NaCl}, 0.1 \mathrm{mM}$ EDTA, 10\% glycerol, 0.5\% Tween 20 supplemented with protease inhibitors (EDTAfree, Roche). Protein content in cell lysates were quantified using Bradford assay and $20 \mu \mathrm{g}$ of proteins were resolved on NuPAGE® Novex ${ }^{\circledR}$ Bis-Tris $4-12 \%$ gels kit (Invitrogen), transferred to PVDF membranes (Trans-blot ${ }^{\circledR}$ Turbo $^{\text {TM }}$ Transfer System, Biorad) and analyzed using chemiluminescence detection (Pierce ${ }^{\mathrm{TM}}$ ECL Western Blotting Substrate). Western blots were performed using the following antibodies: the albumin (1140V7, Kent laboratories), the CYP3A4 (AB1254, Chemicon) and the HSC70 (B-6, sc7298, Santa Cruz Biotechnology).

\subsection{Treatments with xenobiotics and luciferase assay}

The environmental contaminants, the endosulfan (Endo) and fluoranthene (Fluo), and the prototypical inducer of DME gene expression, the benzo[a]pyrene $(\mathrm{B}[\mathrm{a}] \mathrm{P})$ were purchased from Sigma-Aldrich. Twenty four h after lipofection or electroporation, HepaRG cells were treated with $5 \mu \mathrm{M}(\mathrm{B}[\mathrm{a}] \mathrm{P}), 25 \mu \mathrm{M}$ Endo and $50 \mu \mathrm{M}$ Fluo dissolved in DMSO $(0.25 \%$ final concentration of DMSO in medium) during $24 \mathrm{~h}$ prior to the quantification of the luciferase activity (Dual-Glo Luciferase Assay system, Promega). These concentrations were selected based on a previous work from our laboratory demonstrating low effects on cell viability at these concentrations [Quesnot et al., 2016]. The luciferase assay was performed as recommended by the manufacturer's instruction (Promega) and luciferase activities were measured using a luminometer (Centro XS3 LB960, Berthold Technologies).

\subsection{Statistical analyses}

Results were expressed as mean \pm SEM (the standard error of the mean) of at least three independent experiments. Statistically significant variations after treatment were compared with controls using Student's test with Excel software; *p value $<0.05$ and ${ }^{* *} p<0.01$.

\section{Results}

\subsection{Characterization of EPC/diether-based liposomes}

The main characteristics of the liposomes prepared with various ratios of EPC and diether- $\mathrm{NH}_{2}$ $(1 / 2,3 / 2$ and $5 / 2)$ were established (Table 1$)$. The different liposomes exhibited very similar size distributions ranging from 83.8 to $92 \mathrm{~nm}$ and polydispersity indexes of 0.36 to 0.4 suggesting a single population of nanoparticles without formation of aggregates, which was further confirmed by the visualization of isolated EPC/diether liposomes by electron 
microscopy (Figure 1). In contrast, the zeta potential differed significantly between the liposomes (Table 1). While the EPC/diether 3/2 liposomes showed a slightly positive zeta potential at $+13 \mathrm{mV}$, the EPC/diether $1 / 2$ nanoparticles were closed to the neutrality and the EPC/diether 5/2 liposomes exhibited a weak negative charge.

Altogether, these results indicated that the various amounts of EPC and diether- $\mathrm{NH}_{2}$ did not affect the self-assembly of lipids into nanoparticles but, in contrast, allowed the formulation of liposomes characterized by $\sim 90 \mathrm{~nm}$ diameters and weak surface charges.

4.2. Efficient transfection and low toxicity in HepaRG cells using EPC/diether-based liposomes The EPC/diether liposomes were first used to transiently transfect the human progenitor HepaRG hepatoma cells. These hepatic progenitor cells, which express reduced amounts of liver specific functions during proliferation, are capable to commit towards both cholangiocyte and hepatocyte lineages after contact inhibition of the proliferation at confluency [Cerec et al., 2007 , Corlu and Loyer, 2015]. We have previously reported that an efficient gene transfer can be achieved in these progenitor cells using electroporation [Laurent et al., 2010] and a limited set of liposomes [Laurent et al., 2010, 2013]. However, high levels of cytotoxicity have been frequently observed in HepaRG cell cultures using nanoparticles for gene transfer. Thus, we used these cells to first assess the transfection efficiency and toxicity of the EPC/diether liposomes.

The EPC/diether- $\mathrm{NH}_{2}$ liposomes at ratios of $1 / 2,3 / 2$ and $5 / 2$ were used to transfect the pmaxGFP plasmid in HepaRG cells. The cell viability was evaluated using the MTT assay while transfection efficiency was monitored with the percentage of GFP positive cells and the mean of fluorescence (Figure 2 and supporting Figure 2A-2B). The cell viability and transfection efficiencies were compared between cells transfected with the EPC/diether liposomes, and the Lipofectamine ${ }^{\circledR}$, FreeStyle ${ }^{\mathrm{TM}}$ MAX and MACSfectin ${ }^{\circledR}$ reagents, using 4 charge ratios $(R)$.

The cell viability was strongly decreased after transfection with the Lipofectamine ${ }^{\circledR}$ and the FreeStyle ${ }^{\mathrm{TM}}$ MAX regardless of the charge ratios $(R)$ and with the MACSfectin ${ }^{\circledR}$ for the 3 higher $R$ (Figure 2). In contrast, the MACSfectin ${ }^{\circledR}$ at $R=1$ and the $\mathrm{EPC} /$ diether liposomes at $R=$ 1 and 2 did not significantly affect the MTT activities. The cell viability was also slightly reduced following transfection with EPC/diether liposomes at $R=3$ and 4 but remained above $70 \%$ of that found in control cultures.

The detection of GFP positive cells using fluorescent microscopy and flow cytometry indicated that all these transfection reagents allowed GFP expression in various extends in HepaRG progenitor cells (Supporting Figure 2A) with, however, great differences in the transfection 
efficiencies between the reagents and the various charge ratios. The EPC/diether $3 / 2$ and 5/2 liposomes at $R=3$ and $R=4$, and the Lipofectamine ${ }^{\circledR}$ at $R=4$ induced the highest levels of transfection reaching $36.7 \%$ of GFP positive cells for EPC/diether $3 / 2$ liposomes and 39\% for the Lipofectamine ${ }^{\circledR}$ reagent (Figure 2). The transfection efficiencies were much lower using the same EPC/diether lipoplexes at $R=1$ and $R=2$ and the Lipofectamine ${ }^{\circledR}$ reagent at $R=1, R=2$ and $R=4$. The mean of fluorescence reflecting the GFP expression levels in the GFP positive cell population was also found elevated in the cells transfected with the EPC/diether $3 / 2$ and $5 / 2$ liposomes at $R=3$ and $R=4$ but also for the EPC/diether $1 / 2$ liposomes at the same charge ratios while in cells transfected with the Lipofectamine ${ }^{\circledR}$, the mean of fluorescence was much weaker indicating lower expression levels of the GFP in these cells compared to those found in cells transfected with EPC/diether 3/2 and 5/2 liposomes.

The GFP was detected in $\leq 16 \%$ of HepaRG cells transfected with EPC/diether 1/2 liposomes, the MACSfectin ${ }^{\circledR}$ and the FreeStyle ${ }^{\mathrm{TM}}$ MAX reagents (Figure 2 and Supporting Figure $2 \mathrm{~B}$ ) and the $R$ values did not significantly affect the transfection rates. In addition, the fluorescence intensities did not significantly fluctuate with the Lipofectamine ${ }^{\circledR}$, MACSfectin ${ }^{\circledR}$ and FreeStyle ${ }^{\mathrm{TM}} \mathrm{MAX}$ transfection reagents.

Together, these data demonstrated that EPC/diether lipoplexes support efficient plasmid cell uptake and expression of the GFP reporter gene in HepaRG progenitor cells. Furthermore, the EPC/diether 3/2 liposomes yielded the highest transfection efficiencies at $R=3$ with a very mild toxicity compared to the commercial reagents.

\subsection{Efficient transfection of permissive HEK293T cells using EPC/diether-based liposomes}

To further evaluate the ability of EPC/diether liposomes to support transient plasmid transfection in human cells, we compared the cell viability and transfection efficiencies in the HEK293T cells, known to be easily transfected with numerous procedures, using the EPC/diether $3 / 2$ liposomes and the Lipofectamine ${ }^{\circledR}$, MACSfectin ${ }^{\circledR}$ and FreeStyle ${ }^{\mathrm{TM}}$ MAX transfection reagents. As previously observed with the HepaRG progenitor cells, the viability of the HEK293T cells was significantly decreased in a dose-dependent manner with increasing charge ratios. However, the HEK293T cell viability remained much higher following transfection with the commercial reagents compared to that measured in HepaRG cells (Figure 2) while the MTT activities were comparable between the HEK293T and HepaRG cells transfected using the EPC/diether 3/2 liposomes (Figure 3, Supporting Figure 3).

As expected, the percentages of GFP positive HEH293T cells were very high with several transfection formulations since 25 to $90 \%$ of the cells expressed the GFP following transfection with the EPC/diether $3 / 2$ liposomes, the Lipofectamine ${ }^{\circledR}$ and MACSfectin ${ }^{\circledR}$ reagents. In these 
conditions, the GFP expression levels went up with increasing $R$ excepted for the MACSfectin ${ }^{\circledR}$ allowing $92.5 \% \pm 0.24$ of GFP positive cells at $R=3$ and $67.5 \% \pm 0.9$ at $\mathrm{R}=4$. In contrast, the FreeStyle ${ }^{\mathrm{TM}}$ MAX reagent was the less efficient formulation with less than $25 \%$ of GFP positive HEK cells. Furthermore, a good correlation was found between the percentages of GFP positives HEK cells and the means of fluorescence with the 4 transfection reagents demonstrating the correlation between the percentages of GFP positives cells and the GFP expression levels in HEK293T cells. Together, our data further demonstrated that the EPC/diether 3/2 liposomes allowed the very efficient gene transfer with low cytotoxicity in human HEK293T cells.

\subsection{Transfection of an XRE-pGL3 biosensor plasmid in hepatocyte-like HepaRG cells using EPC/diether-based liposomes}

The data demonstrating the efficient transfection of the HepaRG progenitor and HEK293T cells with very low cytotoxicity using the EPC/diether 3/2 liposomes prompted us to evaluate the ability of these liposomes to achieve gene transfer in the differentiated HepaRG cells, which are hepatocyte-like cells difficult to transfect [Laurent et al., 2013]. These metabolically competent cells are obtained following a well-defined procedure of differentiation of the HepaRG progenitor cell population allowing optimal expression of liver specific functions [Cerec et al., 2007 ; Laurent et al., 2013 ; Dubois-Pot-Schneider et al., 2014]. The HepaRG progenitor cells are expanded by cell plating at a low density of $2.6 \times 10^{4}$ cells $/ \mathrm{cm}^{2}$ (Figure $4 \mathrm{~A}$ ) inducing an active proliferation during the first week post-plating. Two weeks after plating, the cells reach the confluency, become quiescence and commit to the cholangiocyte or the hepatocyte cell lineages. The full differentiation of HepaRG hepatocyte- and cholangiocytelike cells is induced by maintaining confluent cells for another two weeks in the same culture medium supplemented with 2\% DMSO [Cerec et al., 2007 ; Laurent et al., 2013 ; Dubois-PotSchneider et al., 2014] (Figure 4A-B). HepaRG hepatocyte- and cholangiocyte-like cells were produced and the hepatocyte phenotype was confirmed by the immunoblotting detection of the albumin and CYP3A4 expression levels throughout the 30 days of culture time course (Figure 4B). As previously demonstrated [Cerec et al., 2007 ; Laurent et al., 2013 ; Dubois-PotSchneider et al., 2014], the albumin was expressed at low amounts in proliferating HepaRG cells at days 1 to 6 after plating but its level increased during the second week post-plating and was slightly enhanced by the addition of DMSO. In contrast, the expression of a major phase I enzyme, the CYP3A4, barely detectable in progenitor cells, was strongly induced by the DMSO stimulation evidencing the differentiation of the HepaRG hepatocyte-cells. 
Using various reagents, we have previously demonstrated that the gene transfer was poorly efficient in differentiated HepaRG cell cultures with low percentages of transfection for cholangiocyte-like cells and virtually no transfected hepatocyte-like cells [Laurent et al., 2010 ; Laurent et al., 2013]. However, we have optimized a protocol of electroporation for HepaRG hepatocyte-like cells [Laurent et al., 2013]. Independently, in order to set up pure cultures of HepaRG hepatocyte-like cells, we have established a procedure to selectively detach these cells while cholangiocyte-like cells remain adherent [Cerec et al., 2007 ; Corlu and Loyer, 2015]. We herein evaluated whether the EPC/diether 3/2 liposomes allowed the transfection of the HepaRG hepatocyte-like cells plated at high density and in culture medium supplemented with 2\% DMSO to maintain expression of the liver specific functions (Figure 4C). The EPC/diether $3 / 2$ liposomes at $R=3$ were used to transfect the pmaxGFP plasmid in HepaRG hepatocyte-like cells $24 \mathrm{~h}$ post-plating and the percentage of GFP positive cells was measured $48 \mathrm{~h}$ later (Figure 4C). In this condition, $29 \% \pm 7$ of HepaRG hepatocyte-like cells expressed the GFP reporter gene. In addition, the cell viability was not affected (data not shown) and the expression of the CYP3A4 was maintained in transfected cells at days 1 and 3 post plating (Figure 4B) demonstrating that the transfection by EPC/diether $3 / 2$ liposomes did not strongly affect the hepatocyte phenotype.

Since the EPC/diether 3/2 liposomes allowed the transfection of a significant fraction of HepaRG hepatocyte-like cells, we decided to develop a HepaRG cell-based assay using the transient transfection of these cells with EPC/diether 3/2 liposomes. We designed a plasmid carrying a XRE consensus sequence regulating the transcription of the luciferase reporter gene in order to detect inductions of Xenobiotic Responsive Element (XRE)-dependent genes upon treatments with drugs. A nucleotide sequence of 46 base pairs derived from previously identified consensus sequences of Xenobiotic Responsive Elements (XRE) [Fujisawa-Sehara et al., 1988] was subcloned upstream of the luciferase coding sequence in the pGL3-basic plasmid (Supporting Figure 4). The XRE-pGL3 plasmid was then transiently transfected in HepaRG hepatocyte-like cells using the EPC/diether 3/2 liposomes, the MACSfectin ${ }^{\circledR}$ and our electroporation procedure (Figure 4D). The luciferase activities were measured in control conditions and cultures treated with benzo[a]pyrene $(\mathrm{B}[\mathrm{a}] \mathrm{P})$, endosulfan (Endo) and fluoranthene (Fluo). The B[a]P and Endo are known to induce expression of phase I enzymes, including the CYP1A1 and CYP3A4, through the binding of the aryl hydrocarbon receptor at least for the $\mathrm{B}[\mathrm{a}] \mathrm{P}$. While the luciferase activities were very low in cells transfected with MACSfectin ${ }^{\circledR}$, the basal levels of luciferase were much higher in cells transfected with the EPC/diether 3/2 liposomes and by electroporation. Moreover, in these two conditions of 
transfection, the luciferase activities were significantly induced by the $\mathrm{B}[\mathrm{a}] \mathrm{P}$ and Endo demonstrating that these two compounds induced XRE-dependent transcriptional activities in HepaRG hepatocyte-like cells. In contrast, the fluoranthene, a polycyclic aromatic hydrocarbon that does not bind to the aryl hydrocarbon receptor, did not affect the luciferase activities.

Together, these data indicated that the transfection of the XRE-pGL3 plasmid using EPC/diether 3/2 liposomes led to the transfer of this plasmid in a number of HepaRG hepatocyte-like cells high enough to evidence the induction of the luciferase reporter gene via the XRE promoter element upon treatment by synthetic compounds.

\section{Discussion}

Self-assembled nanoparticles from cationic lipids and polymers are readily available and form complexes with anionic nucleic acids widely used to transfect eukaryotic cells. This non-viral technology of gene transfer provides at low cost an easily accessible option to study the role and/or regulation of genes by gain or loss of functions using transiently transfected expression plasmids or siRNA targeting mRNAs, respectively. The in vitro transient transfection of plasmids for protein expression shows, however, striking differences in efficiency between cell types using the criteria of the percentage of positive cells expressing the gene of interest and the expression levels among the positive cells. The variable transfection efficiencies are due to the fact that transferred plasmids must overcome intracellular barriers [Zabner et al., 1995] in cells of various shape, size, compositions, metabolic activities and proliferation rate. These biological barriers include the plasma membrane, the escape of endosomes, the degradation by nucleases, the nuclear translocation and the availability for the transcription machinery within the chromatin of the host cells [Lechardeur et al., 2006].

A plethora of cationic lipids and polymers have been synthetized with the goal to facilitate the traffic of the corresponding plasmid/cationic vector complexes across the cell compartments in order to improve the transfection effectiveness and to limit the cytotoxicity [Belmadi et al., 2015], an important drawback of transfection reagents. Our laboratory and others have reported that many cationic compounds employed as synthetic carriers for DNA allow a high cell uptake of plasmids [Laurent et al., 2010 ; Lechardeur and Lukacs, 2006] indicating that the intracellular amounts of plasmid vector was not necessary a limiting step in transfection efficiency while the endosomal escape [Sun et al., 2012 ; Wan Y, et al., 2015] and the nucleocytoplasmic transport [Brunner et al., 2002 ; Gonçalves et al., 2009] of plasmid DNA following non-viral gene transfer remain key parameters for achieving high gene expression. Regarding the nuclear translocation, numerous lines of evidences indicate that high transfection efficiencies are obtained only in actively dividing cells, at least for liposomes [Mortimer et al., 1999 ; Tseng et 
al., 1999] while the cell cycle dependence of gene transfer for polymeric nanoparticles is less clear [Pollard et al. 1998 ; Brunner et al., 2002]. The cell cycle dependence of non-viral gene transfer observed with some nanovectors is most likely due to the fact that in proliferating cells the disruption of the nuclear envelop during mitosis would allow the passive diffusion of exogenous DNA in the cell chromatin and its entrapping in the newly formed nucleus of the daughter cells at the end of the mitosis [Tseng et al., 1999]. For this reason, the transfection efficiencies obtained for quiescent primary cells are usually much weaker than those observed for established proliferating cell lines or even primary cells with a relatively high proliferation rate.

It is well recognized that hepatic cells, especially primary quiescent hepatocytes, are difficult to transfect [Ourlin et al., 1997]. In primary culture, rat hepatocytes upon mitogenic stimulation or mouse hepatocytes that spontaneously undergo 1 or 2 rounds of cell cycle can be transfected at relatively high levels reaching 30 to $40 \%$ using optimized cationic lipids and transfection conditions [Gilot et al., 2002 ; Park et al., 2011]. In contrast, the lipid- and polymer-mediated transfection of expression plasmid vectors in human primary hepatocytes that poorly proliferate upon mitogenic stimulation remains extremely low [Laurent et al., 2013]. Similarly, the proliferating hepatic HepaRG progenitor cells can be efficiently transfected using various cationic lipids and electroporation while the quiescent and highly differentiated hepatocyte-like HepaRG cells are poorly permissive cells to lipofection [Laurent et al., 2010 ; Laurent et al., 2013]. In addition, rodent and human primary hepatocytes as well as differentiated hepatoma cells are very sensitive to toxicity induced by many transfection reagents, which further limits the use of transient transfection in these cell types.

Because of the raising interest in hepatocyte-like HepaRG cells for drug metabolism studies [Kanebratt and Andersson, 2008] and for analyzing the process of differentiation from hepatic progenitors towards hepatocytes [Cerec et al., 2007 ; Dubois-Pot-Schneider et al., 2014], optimization of HepaRG cell transfection has become a pertinent task. In this report, we first characterized the gene delivery and cytotoxicity mediated by liposomes prepared from diether$\mathrm{NH}_{2}$ combined with EPC using proliferating HEK293T and HepaRG cells. Our data demonstrated that EPC/diether lipoplexes support a very efficient expression of the GFP reporter gene in both HEK293T and progenitor HepaRG cells. Furthermore, a striking observation was that these high transfection efficiencies were obtained with very mild toxicities compared to commercial reagents and other liposomes previously used in our laboratory [Laurent et al., 2010]. 
Taking advantage of these non-toxic EPC/Diether- $\mathrm{NH}_{2}$ liposomes, we established a protocol of lipofection for differentiated hepatocyte-like HepaRG cells. In confluent and quiescent differentiated HepaRG cell cultures, we previously demonstrated that the gene transfer was very low with less than $5 \%$ of transfected cholangiocyte-like cells and virtually no transfected hepatocyte-like cells [Laurent et al., 2010 ; Laurent et al., 2013]. The poorly efficient lipofection of cholangiocyte- and hepatocyte-like HepaRG cells is most likely due to their lack of proliferation and the abundant extracellular matrix deposition around these cells observed in this coculture model that may prevent the plasmid cell uptake. In order to favour the lipofection of hepatocyte-like HepaRG cells, we also took advantage of the procedure developed in our laboratory to selectively detached hepatocyte-like cells allowing to set up a pure culture of hepatocyte-like cells [Cerec et al., 2007 ; Laurent et al., 2013]. Interestingly, when pure cultures of hepatocyte-like HepaRG cells are seeded at a high density in culture medium supplemented with $2 \%$ DMSO, a transient and moderate proliferation activity is observed during $48 \mathrm{~h}$ after seeding [Cerec et al., 2007] while the expression of the liver specific functions is well maintained. After proliferating, cells return to quiescence and remain metabolically stable for several weeks. In contrast, when hepatocyte-like cells are plated at low density in culture medium lacking DMSO supplementation, cells immediately re-enter the cell cycle, actively proliferate and rapidly lose their differentiated hepatocyte phenotype through a retrodifferentiation process giving back a bipotent progenitor cell population [Cerec et al., 2007 ; Dubois-Pot-Schneider et al., 2014 ; Corlu and Loyer, 2015]. We hypothesized that EPC/diether liposomes could be used to transfect the enriched population of hepatocyte-like HepaRG cells postulating that the elimination of the extracellular matrix during the selective detachment and the transient proliferation of hepatocyte-like cells could favour the lipofection. Furthermore, the low cytotoxicity of the EPC/diether liposomes observed with HEK293T and proliferating HepaRG cells also appeared as a crucial feature to further improve the transfection efficiency and the overall cell survival during lipofection of HepaRG hepatocyte-like cells. We found that $\sim 30 \%$ of hepatocyte-like HepaRG cells expressed the GFP reporter gene following lipofection using EPC/diether 3/2 liposomes transferring the pmaxGFP plasmid. Importantly, the cell viability and the expression of the CYP3A4 were not significantly affected supporting the conclusion that EPC/diether liposomes provide the first efficient lipofection reagent for hepatocyte-like HepaRG cells without inducing major cytotoxicity.

The most relevant feature of the hepatocyte-like HepaRG cells is their remarkable metabolism capacity especially their ability to metabolize xenobiotics [Anthérieur et al., 2012 ; Jetten et al., 2013], which has been used to develop whole cell biosensors [Pernelle et al. 2011 ; Tsuji et al., 
2014] measuring cell responses and gene inductions with the goal to evidence metabolic pathway activations and toxicity. In this context, we sought to use the EPC/diether liposomemediated lipofection to transiently transfect hepatocyte-like HepaRG cells with a biosensor plasmid containing a Xenobiotic Responsive Element and a minimal promoter driving the transcription of the luciferase reporter gene in order to evidence the induction of Xenobiotic Responsive Element-dependent genes upon drug treatments. The expression of the luciferase was evaluated in untreated hepatocyte-like HepaRG cells or cells treated with the benzo[a]pyrene, a prototypical inducer of cytochrome P450 genes, and two widespread environmental contaminants, the fluoranthene and endosulfan, following lipofection with the MACSfectin ${ }^{\circledR}$ and the EPC/diether $3 / 2$ liposomes and electroporation. The MACSfectin ${ }^{\circledR}$ reagent was used since it allowed the expression of GFP in $\sim 20 \%$ of progenitor HepaRG cells and did not induce significant cytotoxicity, in contrast with the strong cell death obtained after transfection using Lipofectamine ${ }^{\circledR}$ and FreeStyle ${ }^{\mathrm{TM}}$ MAX reagents. The luciferase expression was barely detectable in untreated cells transfected with the MACSfectin ${ }^{\circledR}$ while both EPC/diether liposomes and electroporation achieved quite similar luciferase activities significantly above the background level. These data demonstrated that transfections of the XRE-pGL3 biosensor plasmid using EPC/diether liposomes and electroporation allowed a sufficient overall expression of luciferase in hepatocyte-like HepaRG cells to assess the possible induction of the luciferase activities by exogenous compounds. Following exposure to the benzo[a]pyrene and endosulfan, the luciferase activities were significantly enhanced compared to those measured in untreated cells. Although the luciferase activities did not appear statistically different in cells transfected with EPC/diether liposomes and electroporation upon treatments with benzo[a]pyrene or endosulfan, these activities seemed slightly higher in cells subjected to the electroporation. A possible explanation would be that the electroporation allowed a higher efficiency of gene transfer since we routinely obtain $\sim 75 \%$ of GFP positive cells by electroporation [Laurent et al., 2010 ; Laurent et al., 2013] while we herein report that $\sim 30 \%$ of hepatocyte-like HepaRG cells express the GFP reporter gene following transfection using EPC/diether liposomes. Nevertheless, both procedures of transfection allowed an efficient transfer of the XRE-pGL3 biosensor plasmid in the differentiated HepaRG cells, the basal expression of luciferase and its transcriptional induction following treatments with benzo[a]pyrene or endosulfan.

The benzo[a]pyrene is a polycyclic aromatic hydrocarbon that binds to the aryl hydrocarbon receptor and translocates to the nucleus to induce expression of phase I enzymes including the CYP1A1. The endosulfan, an organochlorine insecticide and an endocrine disruptor is also 
known to induce the CYP3A4. In contrast, the fluoranthene, a polycyclic aromatic hydrocarbon that does not bind to the aryl hydrocarbon receptor, did not affect the luciferase activities. The induction of luciferase activities upon treatment with the benzo[a]pyrene and endosulfan strongly supports the conclusion that the transfection of xenobiotic inducible biosensor plasmids in hepatocyte-like HepaRG cells using EPC/diether liposomes could represent a suitable whole-cell based biosensor assay to identify drugs inducing XRE regulated genes in metabolically competent cells.

\section{Acknowledgements}

This work was funded by the Agence Nationale de la Recherche (ANR, contract NISTEC ANR09-CESA-003-002), the Institut National de la santé et de la Recherche Médicale (Inserm) and the Centre National de la Recherche Scientifique (CNRS). Nicolas Quesnot received a fellowship from the Région Bretagne and Ligue contre le Cancer Grand-Ouest, Comité Départemental des Côtes d'Armor (22).

\section{References}

Abdel-Razzak, Z., Loyer, P., Fautrel, A., Gautier, JC., Corcos, L., Turlin, B., Beaune, P., Guillouzo, A., 1993. Cytokines down-regulate major cytochrome P450 in primary culture of human hepatocytes. Mol. Pharmacol. 44, 707-715.

Aninat, C., Piton, A., Glaise, D., Le Charpentier, T., Langouet, S., Morel, F., GuguenGuillouzo, C., and Guillouzo, A., 2006. Expression of cytochrome P450, conjugating enzymes and nuclear receptors in human hepatoma HepaRG cells. Drug Metab. Dispos. 34, 75-83.

Anthérieu, S., Chesné, C., Li, R., Guguen-Guillouzo, C., Guillouzo, A., 2012. Optimization of the HepaRG cell model for drug metabolism and toxicity studies. Toxicol. In Vitro 8, 1278-85. Belmadi, N., Midoux, P., Loyer, P., Passirani, C., Pichon, C., Le Gall T., Jaffrès, P-A., Lehn, P., Montier, T., 2015. Synthetic vectors for gene delivery : An overview of their evolution depending on routes of administration. Biotechnol. J. 10, 1370-1389.

Blagus, T., Zager, V., Cemazar, M., Sersa G., Kamensek, U., Zegura, B., Nunic, J., Filipic, M., 2014. A cell-based biosensor system HepG2CDKN1A-DsRed for rapid and simple detection of genotoxic agents. Biosens. Bioelectron. 64, 102-111.

Brunner, S., Sauer, T., Carotta, S., Cotten, M., Saltik, M.,Wagner, E., 2000. Cell cycle dependence of gene transfer by lipoplex, polyplex and recombinant adenovirus. Gene Ther. 7, 401-407.

Casabar, R.C., Das, P.C., Dekrey, G.K., Gardiner, C.S., Cao, Y, Rose, R.L., Wallace, A.D., 2010. Endosulfan induces CYP2B6 and CYP3A4 by activating the pregnane $\mathrm{X}$ receptor. Toxicol. Appl. Pharmacol. 245, 335-43. 
Cerec, V., Glaise, D., Garnier, D., Morosan, S., Turlin, B., Drenou, B., Gripon, P., Kremsdorf, D., Guguen-Guillouzo, C., Corlu, A., 2007. Transdifferentiation of hepatocyte-like cells from the human hepatoma HepaRG cell line through bipotent progenitor. Hepatology 45, 957-967. Corlu, A., Loyer, P., 2015. Culture conditions promoting hepatocyte proliferation and cell cycle synchronization. Protocols in in vitro hepatocyte research. Methods Mol. Biol. 1250, 27-51.

Desmots, F., Rissel, M., Gilot, D., Lagadic-Gossmann, D., Morel, F., Guguen-Guillouzo, C., Guillouzo, A., Loyer, P., 2002. Pro-inflammatory cytokines tumor necrosis factor alpha and interleukin- 6 and survival factor epidermal growth factor positively regulate the murine GSTA4 enzyme in hepatocytes. J. Biol. Chem. 277, 17892-900.

Dubois-Pot-Schneider, H., Fekir, K., Coulouarn, C., Glaise, D., Aninat, C., Jouarnen, K., Le Guével, R., Kubo, T., Ishida, S., Morel, F., Corlu, A., 2014. Inflammatory cytokines promote the retrodifferentiation of tumor-derived hepatocyte-like cells to progenitor cells. Hepatology 60, 2077-90.

Dumont, J., Jossé, R., Lambert, C., Anthérieu, S.; Laurent, V., Loyer, P., Robin MA, Guillouzo A., 2010. Preferential induction of the AhR gene battery in HepaRG cells after a single or repeated exposure to heterocyclic aromatic amines. Tox. Appl. Pharmacol. 249, 91-100.

Fardel, O., Loyer, P., Morel, F., Ratanasavanh, D., Guillouzo, A., 1992. Modulation of multidrug resistance gene expression in rat hepatocytes maintained in various culture conditions. Biochem. Pharmacol. 44, 2259-2262.

Felgner, P.L., Gadek, T.R., Holm, M., Roman, R., Chan, H.W., Wenz, M., Northrop, J.P., Ringold, G.M., Danielsen, M., 1987. Lipofection: a highly efficient, lipid-mediated DNAtransfection procedure. Proc. Natl. Acad. Sci. USA 84, 7413-7417.

Fery, Y., Mueller, S.O., Schrenk, D., 2010. Development of stably transfected human and rat hepatoma cell lines for the species-specific assessment of xenobiotic response enhancer module (XREM)-dependent induction of drug metabolism. Toxicol. 277, 11-19.

Fujisawa-Sehara, A., Yamane, M., Fujii-Kuriyama, Y., 1988. A DNA-binding factor specific for xenobiotic responsive elements of P-450c gene exists as a cryptic form in cytoplasm: Its possible translocation to nucleus. Proc. Natl. Acad. Sci. USA 85, 5859-5863.

Gilot, D., Miramon, M.L., Benvegnu, T., Ferrières, V., Loréal, O., Guguen-Guillouzo, C., Loyer, P., 2002. Cationic lipids derived from glycine betaine promote efficient and non-toxic gene transfection in cultured hepatocytes. J. Gene Med. 4, 415-427.

Gonçalves, C., Ardourel, M.-Y., Decoville, M., Breuzard, G., Midoux, P., Hartmann, B., Pichon, C., 2009. An optimized extended DNA kappa B site that enhances plasmid DNA nuclear import and gene expression. J. Gene Med. 11, 401-411. 
Gripon, P., Rumin, S., Urban, S., Le Seyec, J., Glaise, D., Cannie, I., Guyomard, C., Lucas, J., Trepo, C., and Guguen-Guillouzo, C., 2002. Infection of a human hepatoma cell line by hepatitis B virus. Proc Natl Acad Sci USA 99, 15655-15660.

Guillouzo, A., and Guguen-Guillouzo, C., 2008. Evolving concepts in liver tissue modeling and implications for in vitro toxicology. Expert Opin. Drug. Metab. Toxicol. 4, 1279-1294.

Hashizume, T., Yoshitomi, S., Asahi, S., Uematsu, R., Matsumura, S., Chatani, F., Oda, H., 2010. Advantages of human hepatocyte-derived transformants expressing a series of human cytochrome P450 isoforms for genotoxicity examination. Toxicol. Sci. 116, 488-497.

Heyes, J., Palmer, L., Bremner, K., MacLachlan, I., 2005. Cationic lipid saturation influences intracellular delivery of encapsulated nucleic acids. J. Control. Rel. 107, 276-287.

Jetten, M.J.A., Kleinjans, J.C.S., Claessen, S.M., Chesné, C., van Delft, J.H.M., 2013. Baseline and genotoxic compound induced gene expression profiles in HepG2 and HepaRG compared to primary human hepatocytes. Toxicol. In Vitro 27, 2031-2040.

Jossé, R., Aninat, C., Glaise, D., Dumont, J., Fessard, V., Morel, F., Poul, JM., GuguenGuillouzo, C., Guillouzo, A., 2008. Long-term functional stability of HepaRG hepatocytes and use for chronic toxicity and genotoxicity studies. Drug Metab. Dispos. 36, 1111-1118.

Jover, R., Bort, R., Gomez-Lechon, M.J., Castell, J.V., 1998. Re-expression of C/EBP alpha induces CYP2B6, CYP2C9 and CYP2D6 genes in HepG2 cells. FEBS Lett. 431, 227-230.

Kanebratt, K.P., Andersson, T.B., 2008. Evaluation of HepaRG cells as an in vitro model for human drug metabolism studies. Drug Metab. Dispos. 36, 1444-52.

Kelly, J.H., 1994. Permanent human hepatocyte cell line and its use in a liver assist device (LAD). US patent No. 5,290,684.

Lainé, C., Mornet, E., Lemiègre, L., Montier, T., Cammas-Marion, S., Neveu, C., Carmoy, N., Lehn, P., Benvegnu, T., 2008. Folate-equipped pegylated archaeal lipid derivatives : Synthesis and transfection properties. Chem. Eur. J. 14, 8330-8340.

Langouet, S., Corcos L., Abdel-Razzak Z., Loyer P., Ketterer B., Guillouzo A., 1995. Up regulation of glutathione S-transferases alpha by interleukin 4 in human hepatocytes in primary culture. Biochem. Biophys. Res. Commun. 216, 793-800.

Laurent, V., Fraix, A., Montier, T., Cammas-Marion, S., Ribault, C., Benvengu, T., Jaffres, PA., and Loyer, P., 2010. Highly efficient gene transfer into hepatocyte-like HepaRG cells : new means for drug metabolism and toxicity studies. Biotechnol. J. 5, 314-320.

Laurent, V., Glaise, D., Nubel, T, Gilot, D., Corlu, A., and Loyer, P., 2013. Highly Efficient SiRNA and Gene Transfer into Hepatocyte-Like HepaRG Cells and Primary Human 
Hepatocytes: New Means for Drug Metabolism and Toxicity Studies. Methods Mol. Biol. 987, 295-314.

Lechardeur, D., Lukacs, G. L., 2006. Nucleocytoplasmic transport of plasmid DNA: A perilous journey from the cytoplasm to the nucleus. Hum. Gene Ther. 17, 882-889.

Legendre, C., Hori, T., Loyer, P., Aninat, C., Ishida, S., Glaise, D., Lucas-Clerc, C., Boudjema, K., Guguen-Guillouzo, C., Corlu, A., Morel, F., 2009. Drug-metabolising enzymes are downregulated by hypoxia in differentiated human hepatoma HepaRG cells: HIF1-alpha involvement in CYP3A4 repression. Eur. J. Cancer 12, 2882-2892.

Liu, D., Qiao, W., Li, Z., Zhang, S., Cheng, L., Jin, K., 2006. Synthetic diether-linked cationic lipids for gene delivery. Chem. Biol. Drug Des. 67, 248-251.

Mortimer, I., Tam, P., MacLachlan, I., Graham, R.W., Saravolac, E.G., Joshi, P., 1999. Cationic lipid-mediated transfection of cells in culture requires mitotic activity. Gene Ther. 6, 403-411. Ourlin, J. C., Vilarem, M. J., Daujat, M., Harricane, M.C., Domergue, J., Joyeux, H., Beaulieux, J., Maurel, P., 1997. Lipid-mediated transfection of normal adult human hepatocytes in primary culture. Anal. Biochem. 247, 34-44.

Park, J-S., Surendran, S., Kamendulis, L.M., Morral, N., 2011. Comparative nucleic acid transfection efficacy in primary hepatocytes for gene silencing and functional studies. BMC Research Notes 4, 1-8.

Pernelle, K., Le Guevel, R., Glaise, D., Stasio, C.G., Le Charpentier, T., Bouaita, B., Corlu, A., Guguen-Guillouzo, C., 2011. Automated detection of hepatotoxic compounds in human hepatocytes using HepaRG cells and image-based analysis of mitochondrial dysfunction using JC-1 dye. Toxicol. Appl. Pharmacol. 254, 256-266.

Pollard, H., Remy JS, Loussouarn G, Demolombe S, Behr J.P., Escande D., 1998. Polyethylenimine but not cationic lipids promotes transgene delivery to the nucleus in mammalian cells. J. Biol. Chem. 273, 7507-7511.

Quesnot, N., Rondel, K., Martinais, S., Audebert, M., Glaise, D., Morel, F., Loyer, P., Robin, M-A., 2016. Evaluation of genotoxicity using automated detection of gammaH2AX in metabolically competent HepaRG cells. Mutagenesis 1, 43-50.

Ren, T., Liu, D., 1999. Synthesis of diether-linked cationic lipids for gene delivery. Bioorg. Med. Chem. Lett. 9, 1247-1250.

Sun, X., Lui, C., Lui, D., Li, P., Zhang, N., 2012. Novel biomimetic vectors with endosomal escape agent enhancing gene transfection efficiency. Int J. Pharm. 425, 62-72.

Suter, W., 2006. Predictive value of in vitro safety studies. Curr. Opin. Chem. Biol. 10, 362366. 
Tseng, W. C., Haselton, F. R., Giorgio, T. D., 1999. Mitosis enhances transgene expression of plasmid delivered by cationic liposomes. Biochim. Biophys. Acta 1445, 53-64.

Tsuji, S., Kawamura, F., Hayashi, A., Ohbayashi, T., Kazuki, Y., Chesné, C., Oshimura, M., Tada, M., 2014. Dual-color fluorescence imaging to monitor CYP3A4 and CYP3A7 expression in human hepatic carcinoma HepG2 and HepaRG cells. PLosOne, 2014, 8, e104123.

Wan, Y., Moyle, P.M., Toth, I., 2015. Endosome escape strategies for improving the efficacy of oligonucleotide delivery systems. Curr Med Chem. 22, 3326-46.

Wilkening, S., Stahl, F., Bader, A., 2003. Comparison of primary human hepatocytes and hepatoma cell line HepG2 with regard to their biotransformation properties. Drug Metab. Dispos. 31, 1035-1042.

Zabner, J., Fasbender, A. J., Moninger, T., Poellinger, K. A., Welsh, M. J., 1995. Cellular and molecular barriers to gene transfer by a cationic lipid. J. Biol. Chem. 270, 18997-19007.

\section{Figure legends}

Figure 1: DLS size measurement (A) and TEM imaging for EPC/diether 1/2 liposomes (B) and lipoplexes at $R=1$ using the pmaxGFP plasmid (C). 

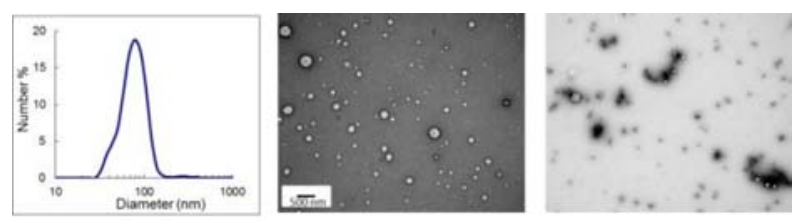

Figure 1

\section{Figure 2: Transient transfection of progenitor HepaRG cells and toxicity evaluation using}

EPC/diether-based liposomes. The liposomes of EPC and diether- $\mathrm{NH}_{2}(3 / 2,5 / 2$ and 1/2, wt/wt) and the reagents Lipofectamine ${ }^{\circledR}$, FreeStyle ${ }^{\mathrm{TM}}$ MAX and MACSfectin ${ }^{\circledR}$ were used to transfect the pmaxGFP plasmid into progenitor HepaRG cells at 4 different charge ratios $(R)$. The cell viability was measured using the MTT assay and expressed in percentage of the MTT activity measured in non-transfected control cells (A). The transfection efficiency was monitored by visualizing the percentage of GFP positive cells in fluorescence microscopy (B and Supporting Figure 2) quantified by flow cytometry (B). The means of fluorescence reflecting the levels of GFP expression in positive cells were also measured (C). Values represent the average of at least 3 independent experiments ( \pm S.E.M). Statistics: A) ${ }^{* *} p<0.01$, significant decrease in cell viability with $\mathrm{EPC} /$ diether- $\mathrm{NH}_{2} 3 / 2,5 / 2$ and $1 / 2(R=3$ and $R=4)$ liposomes, Lipofectamine ${ }^{\circledR}($ all $R)$, MACSfectin ${ }^{\circledR}(R=2, R=3$ and $R=4)$ and FreeStyle ${ }^{\mathrm{TM}}$ MAX (all $R$ ) compared to control cultures; B) ${ }^{* *} p<0.01$, the highest percentages of GFP positive cells obtained with the EPC/diether- $\mathrm{NH}_{2} 5 / 2(R=3)$ and $3 / 2(R=4)$ liposomes and the Lipofectamine ${ }^{\circledR}(R=4)$ compared to the EPC/diether- $\mathrm{NH}_{2}$ 1/2 liposomes, the MACSfectin ${ }^{\circledR}$ and FreeStyle ${ }^{\mathrm{TM}} \mathrm{MAX}($ all $\left.R) ; \mathrm{C}\right){ }^{* *} p<0.01$, the highest means of fluorescence obtained with 
the EPC/diether- $\mathrm{NH}_{2} 5 / 2,3 / 2$ and $1 / 2(R=3$ and $R=4)$ liposomes compared to all other conditions.

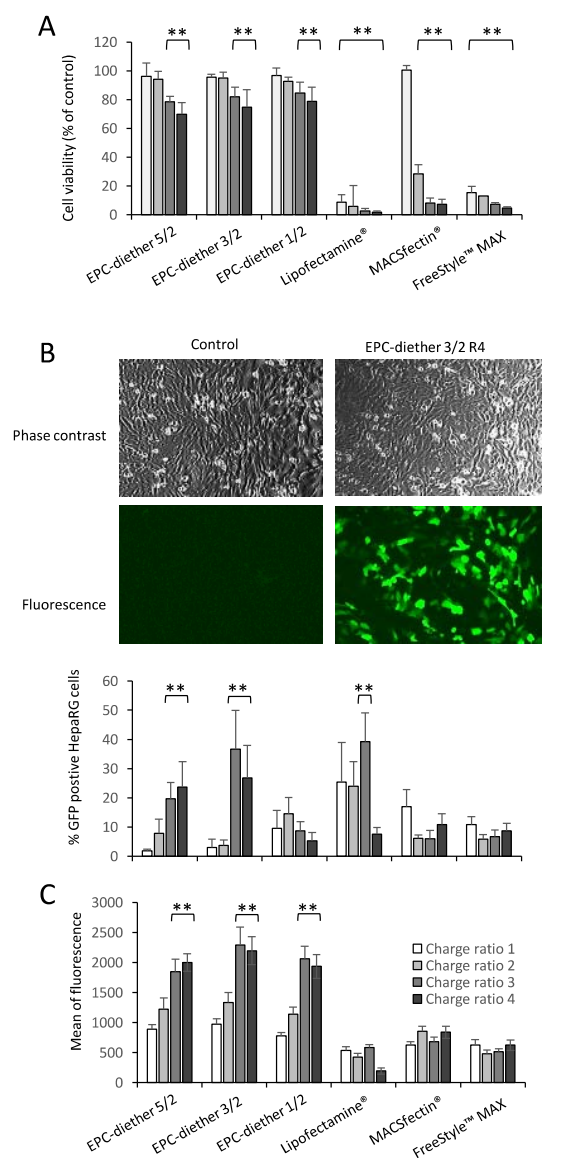

Figure 3: Transient transfection of HEK293T cells using EPC/diether-based liposomes.

The liposomes of EPC and diether- $\mathrm{NH}_{2}(3 / 2 \mathrm{wt} / \mathrm{wt})$ and the reagents Lipofectamine $\AA$, FreeStyle ${ }^{\mathrm{TM}}$ MAX and MACSfectin ${ }^{\circledR}$ were used to transfect the pmaxGFP plasmid into HEK293T cells at 4 different charge ratios $(R)$. The cell viability was measured using the MTT assay and expressed in percentage of the MTT activity measured in non-transfected control cells (A). The transfection efficiency was monitored by visualizing the percentage of GFP positive cells in fluorescence and phase contrast microscopy using Egg-PC/diether- $\mathrm{NH}_{2} 3 / 2$ liposomes (A and Supporting Figure 3) compared to transfection efficiencies in cells transfected with the Lipofectamine ${ }^{\circledR}$, FreeStyle ${ }^{\mathrm{TM}}$ MAX and MACSfectin ${ }^{\circledR}$ (Supporting Figure 3 A-E). Percentage of positive cells (B) and means of fluorescence were quantified by flow cytometry (C). Values represent the average of at least 3 independent experiments ( \pm S.E.M). Statistics: A) ${ }^{*} p<0.01$, significant decrease in cell viability with the EPC/diether- $\mathrm{NH}_{2} 3 / 2(R=3$ and $R=4)$, the Lipofectamine ${ }^{\circledR}($ all $R), \operatorname{MACSfectin}{ }^{\circledR}(R=2, R=3$ and $R=4)$ and FreeStyle ${ }^{\mathrm{TM}}$ MAX 
(all $R$ ) compared to control cultures; B) ${ }^{* *} p<0.01$, the highest percentages of GFP positive cells obtained with the EPC/diether- $\mathrm{NH}_{2} \quad 3 / 2 \quad(R=2, R=3$ and $R=4)$ liposomes, the Lipofectamine ${ }^{\circledR}(R=2, R=3$ and $R=4)$ and MACSfectin ${ }^{\circledR}(R=3)$, and $\left.\mathrm{C}\right){ }^{*} p<0.01$, the highest means of fluorescence obtained with the EPC/diether- $\mathrm{NH}_{2} 3 / 2$ and $1 / 2(R=4)$ liposomes and the Lipofectamine ${ }^{\circledR}(R=4)$.

A
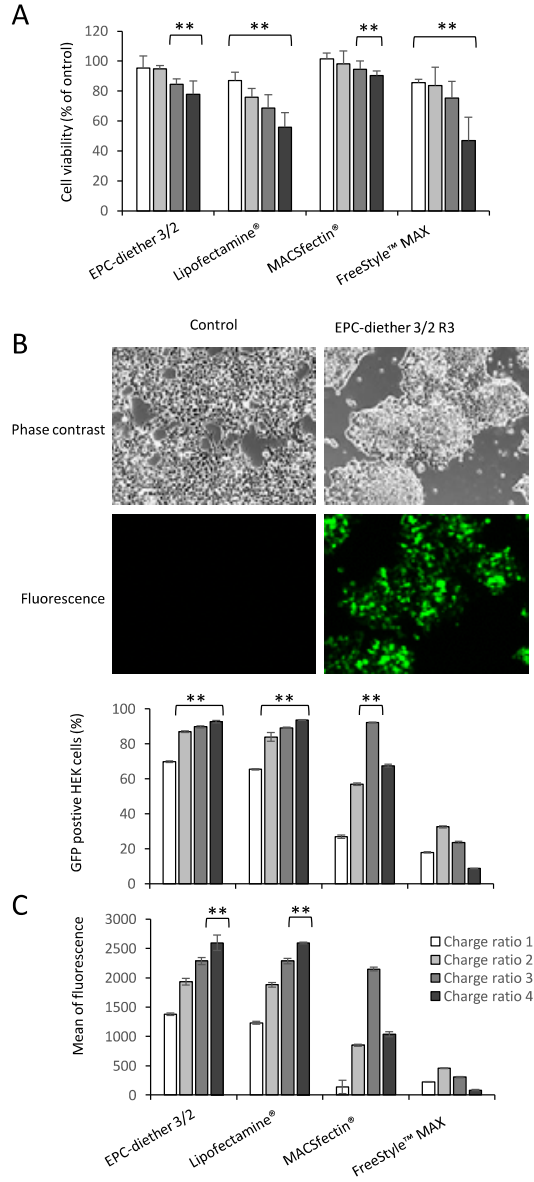

Figure 3

Figure 4: Transfection of XRE-pGL3 biosensor and pmaxGFP plasmids in hepatocytelike HepaRG cells using EPC/diether-based liposomes. Phase contrast microscopy of HepaRG cells at different times after cell seeding (A): bipotent hepatic progenitors actively proliferating at day 2, subconfluent progenitors at day 7 and hepatocyte- (Hep) and cholangiocyte-like (BC) cells at day 30 post-seeding maintained in culture medium in absence (-DMSO) or presence (+DMSO) of $2 \%$ DMSO. Time-course analysis of two liver specific functions, the albumin and CYP3A4, detected by immunoblotting in the whole HepaRG cell populations over the 30 days of the differentiation procedure $(\mathrm{B}$, left panel). Expression of CYP3A4 in pure hepatocyte-like HepaRG cells purified from the mixed population of 
hepatocyte- and cholangiocyte-like cells at day 30 post-seeding and cultured at high density in medium supplemented with 2\% DMSO for 1 and 3 days (B, right panel). Immunoblotting of HSC-70 was used to demonstrate the equal loading of total proteins in each lane. Detection of GFP positive hepatocyte-like HepaRG cells visualized by fluorescence and contrast microscopy following transfection with EPC/diether- $\mathrm{NH}_{2} 3 / 2$ liposomes and pmaxGFP plasmid (C). Ratio between firefly versus renilla luminescence signal in arbitrary unit (A.U.) in hepatocyte-like HepaRG cells transfected with the XRE-pGL3 biosensor and pRL SV40 plasmids using the EPC/diether- $\mathrm{NH}_{2} 3 / 2$ liposomes and the MACSfectin ${ }^{\circledR}$ or using electroporation procedure (Electrop.) (D). Transfected cells were treated with vehicle (Ctrl, $0.25 \%$ final concentration of DMSO in medium) or benzo[a]pyrene $(\mathrm{B}[\mathrm{a}] \mathrm{P})$ at $5 \mu \mathrm{M}$, endosulfan (Endo) at $50 \mu \mathrm{M}$ and fluoranthene (Fluo) at $50 \mu \mathrm{M}$. Values represent the average of at least 3 independent experiments ( \pm S.E.M). Statistics: D) ${ }^{* *} p<0.01$, significant increase in the luciferase activities in HepaRG-like hepatocyte cells transfected with the EPC/diether- $\mathrm{NH}_{2} 3 / 2$ liposomes $(R=3)$ or electroporated (Electrop.) upon treatment with $\mathrm{B}[\mathrm{a}] \mathrm{P}$ and Endo compared to control cultures.

A
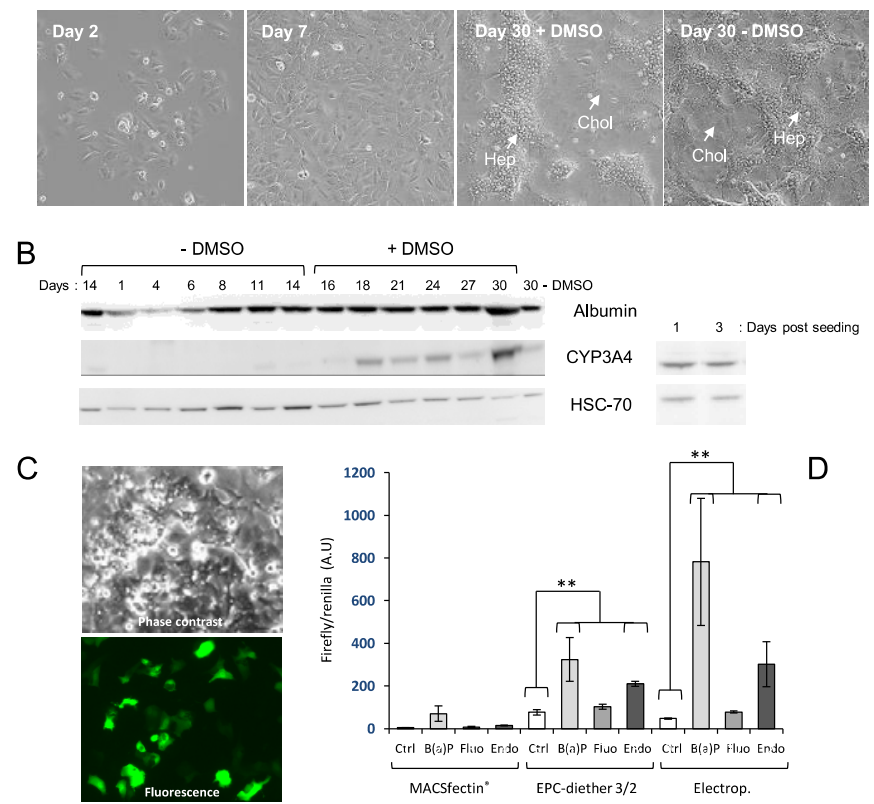
Table 1: Characteristics of the EPC/diether liposomes. ${ }^{a}$ Hydrodynamic diameter measured by DLS. ${ }^{\mathrm{b}}$ Polydispersity index of the nanoparticle size measured by DLS. ${ }^{\mathrm{c}}$ Zeta potential $(\zeta)$ measured by zetametry.

Table 1. Characteristics of the egg phosphatidylcholine/diether- $\mathrm{NH}_{2}$ liposomes.

\begin{tabular}{|c|c|c|c|}
\hline Entry & $\begin{array}{l}\mathrm{D}_{\mathrm{h}}{ }^{\mathrm{a}} \\
(\mathrm{nm})\end{array}$ & PDI ${ }^{b}$ & $\begin{array}{c}\zeta^{c} \\
(\mathrm{mV})\end{array}$ \\
\hline EPC/diether $1 / 2$ & 83.8 & 0.392 & $+3 \pm 6$ \\
\hline EPC/diether $3 / 2$ & 92 & 0.361 & $+13 \pm 6$ \\
\hline EPC/diether $5 / 2$ & 92 & 0.406 & $-12 \pm 6$ \\
\hline
\end{tabular}

